\title{
Histidine-Tryptophan--Ketoglutarate Solution as a Neuroprotective Against Ischemia/Reperfusion Injury
}

\author{
Jiun Hsu ${ }^{1}$, Chih-Hsien Wang ${ }^{2}$, Shu-Chien Huang ${ }^{2}$, Yung-Wei Chen ${ }^{1}$, Sheng-Pin Yu ${ }^{1}$, Juey-Jen \\ Hwang', Jou-Wei Lin', Ming-Chieh Ma", Yih-Sharng Chen ${ }^{2 *}$. \\ ${ }^{1}$ Department of Cardiovascular Surgery, National Taiwan University Hospital Yunlin branch, Yunlin, Taiwan. \\ ${ }^{2}$ Department of Cardiovascular Surgery, National Taiwan University Hospital and National Taiwan \\ University College of Medicine, Taipei, Taiwan. \\ ${ }^{3}$ Department of Cardiovascular Medicine, National Taiwan University Hospital Yunlin branch, Yunlin, \\ Taiwan. \\ ${ }^{4}$ School of Medicine, Fu-Jen Catholic University, New Taipei, Taiwan. \\ * Correspondence: e-mail: yschen1234@gmail.com, address: Department of Cardiovascular Surgery, No.7, \\ Chung Shan S. Rd., Zhongzheng Dist., Taipei City 10002, Taiwan
}

\begin{abstract}
Ischemic neuron loss contributes to brain dysfunction in patients with cardiac arrest (CA). Histidine-tryptophan-ketoglutarate (HTK) solution is a preservative used during organ transplantation. Can HTK also protect neurons from severe hypoxia ( $\mathrm{SH}$ ) following CA? We isolated rat primary cortical neurons and induced SH with or without HTK. Changes in caspase-3, hypoxia-inducible factor 1-alpha (HIF-1 $\alpha$ ), and NADPH oxidase-4 (NOX4) expression were evaluated at different time points till $72 \mathrm{~h}$. Using a rat asphyxia model, we induced CA-mediated brain damage and then completed resuscitation. HTK or sterile saline was administered into the left carotid artery. Neurological deficit scoring and mortality were evaluated for 3 days. Then the rats were sacrificed for evaluating NOX4 and $\mathrm{H} 2 \mathrm{O} 2$ level in blood and brain. In the in vitro study, HTK attenuated $\mathrm{SH}$ - and $\mathrm{H}_{2} \mathrm{O} 2$-mediated cytotoxicity in a volume- and time-dependent manner, associated with persisted HIF- $1 \alpha$ expression, reductions in procaspase-3 activation and NOX4 expression. The inhibition of HIF-1 $\alpha$ abrogated HTK's effect on NOX4. In the in vivo study, neurological scores were significantly improved by HTK. H2O2 level, NOX4 activity and NOX4 gene expression were all decreased in the brain specimen of HTK-treated rats. Our results suggest that HTK acts as an effective neuroprotective solution.
\end{abstract}

Keywords: keyword 1; brain protection 2; HTK 3; cardiac arrest 4; hypoxic injury 5; HIF-1 $\alpha$

\section{Introduction}

In previous studies we proved that extracorporeal cardiopulmonary resuscitation (ECPR) could improve survival rates and neurological outcomes, compared with conventional cardiopulmonary resuscitation (CPR).[1,2] Hypothermia after cardiac arrest (CA) could improve neurological outcomes, but brain damage caused by hypoperfusion and reperfusion injuries remains the leading cause of death among patients who survived CA. In a previous study, intensive care was withdrawn in $30.9 \%$ of CA survivors because of poor neurological outcomes.[3] This finding was compatible with our own experiences. In our cardiac surgery practice, we use a cardioplegic solution to protect patients' hearts when they were stopped from beating. This practice led us to wonder about potential neuroplegic solutions for brain protection and to prevent ischemic injuries following CA. Cardiac surgeons have used deep hypothermia to overcome ischemia during CA that is induced for the purpose of aortic arch surgery since the 1970s. Direct brain perfusion (retrograde or antegrade) 
was developed later in order to provide continuous hypothermic perfusion of the brain. Unfortunately, there is no robust evidence to support available pharmacological protections.[4]

Histidine-tryptophan-ketoglutarate (HTK) solution was developed in the 1960s as an organ preservation and cardioplegic solution.[5] HTK is a low-viscosity fluid with an electrolyte consistency similar to intracellular fluid. Histidine has a large buffering capacity that helps prevent the development of acidosis during the ischemic period. Tryptophan makes the cell membrane more stable, and ketoglutarate is a substrate in Kreb's cycle and facilitates high-energy phosphate formation during ischemia while also inhibiting glycolysis. HTK solution provides excellent and prolonged protection in hypothermic conditions and is now used increasingly for intra-abdominal organ preservation.[6] But there are no reports of the usage of HTK for brain protection during ischemia. Due to the high buffer capacity and membrane stabilizing characteristics of HTK, we considered that HTK might help protect the central nervous system from periods of ischemia and ischemia-reperfusion injuries.

Hypoxia-inducible factor 1 (HIF-1) was identified in 1992 as a factor that responds within hypoxic environments,[7] and its effects on cells during stress conditions were studied extensively thereafter. HIF-1 becomes functional once the $\alpha$ and $\beta$ subunits form a heterodimer.[8] The $\alpha$ subunit is constantly consumed under normoxic conditions via the following sequence: hydroxylation by prolyl hydroxylase, ubiquitination by the VHL complex, and degradation by proteasomes. Under hypoxic or stress conditions, the $\alpha$ subunit enters the nucleus and, together with the $\beta$ subunit, forms a complex to bind the hypoxia-response-element (HRE) and activate target genes. The genes influenced by HIF-1 provide protective effects on cell survival while also facilitating apoptosis or apopnecrosis in different hypoxic environments. HIF-1 also can bind to the promoter of the caspase-3 gene,[9] thereby increasing the expression of pro-caspase-3. However, its relationship to increased apoptosis still requires clarification. When faced with a hypoxic environment, cells will try to maintain adequate amounts of superoxide by increasing the number of enzymes that produce it, and NADPH oxidase 4(NOX4) is the main connection to this process.[10] HIF-1 increases the expression of NOX4 by binding to HRE at the gene promoter region.[11] A gene knock out study that focused on ischemia-reperfusion injury of heart cells also showed decreased levels of HIF-1, related to the decreased NADPH oxidase activity.[12]

There were two parts to this study. The first part was an in vitro experiment using neural cells harvested from embryonic rats. Here we tried to validate the hypothesis that HTK solution has neuroprotective capabilities during ischemic periods, similar to its cardiac protective effects. Using different concentrations of HTK, we evaluated the effects of hypoxia and $\mathrm{H} 2 \mathrm{O} 2$ exposure using biomarkers, cell viability tests, and gene expression.

The second part of the study consisted of an in vivo study using the rat asphyxial CA (aCA) model which was developed in the 1980s to evaluate the effects of CA resulted from asphyxia and to build a model of brain damage for evaluation of resuscitation methods in rats.[13] Rats were asphyxiated for 4.5 or $6.5 \mathrm{~min}$, and the asphyxiated rats were separated into two groups. Under the same resuscitation protocol, HTK or normal saline was administered to the study group or control group, respectively, via a cannula inserted into the left carotid artery and designed to achieve brain perfusion during the first minute of asphyxia. We evaluated the resuscitation success rate and neurological recovery during the first $72 \mathrm{~h}$ after successful resuscitation, and NOX4 and H2O2 concentrations in both groups, after the rats were sacrificed at $72 \mathrm{~h}$.

\section{Materials and Methods}

The present study was conducted by the Institutional Animal Care and Use Committee ( IACUC), number 20100341, that was approved on March 18, 2011. 
Cortical neurons were isolated from embryonic Wistar rats (embryonic days 16 and 17), as described previously.[14] All animal treatments were approved by the Animal Care Committee of Fu Jen Catholic University. In brief, after anesthetizing the pregnant dam with halothane, the embryonic rats were removed and immediately rinsed in a neurobasal medium. Under a dissecting microscope, the embryonic brain cortex was carefully removed, soaked in $0.1 \mathrm{~m}$ phosphate-buffered saline (PBS, pH 7.4), containing $0.6 \%$ glucose, collected by centrifugation, and treated with trypsin for $15 \mathrm{~min}$ at $37^{\circ} \mathrm{C}$. After neutralizing the trypsin with trypsin inhibitor for $5 \mathrm{~min}$, a cell suspension was prepared by repeated passage through a pipette and filtration through an $80 \mu \mathrm{m}$ nylon mesh. This suspension was then diluted with neurobasal medium containing B-27, $0.5 \mathrm{mM}$ glutamine (Merck, Taiwan branch), $25 \mu \mathrm{M}$ glutamate (Merck), $100 \mathrm{IU} / \mathrm{mL}$ penicillin, and $100 \mathrm{mg} / \mathrm{mL}$ streptomycin. The cells were counted by staining with trypan blue, diluted to a density of 106 cells $/ \mathrm{mL}$ in the same medium, and plated onto poly-d-lysine-precoated dishes. The cells were cultured at $37{ }^{\circ} \mathrm{C}$ in $21 \% \mathrm{O} 2$ and $5 \% \mathrm{CO} 2$ in a humidified incubator (NU-5700, NuAire, Plymouth, MN, USA) for 12 days in vitro (DIV) to mature. All chemicals and culture medium were obtained from Thermo Fisher Scientific (Waltham, MA, USA), unless otherwise indicated.

Induction of severe hypoxia (SH).

After DIV 12, the cultured neurons were divided into two groups. For SH treatment, the cultures were exposed to $2 \% \mathrm{O} 2$ and $5 \% \mathrm{CO} 2$ at $37^{\circ} \mathrm{C}$ in an O2-controlled incubator (NU-5731, NuAire) for up to $72 \mathrm{~h}$. This concentration ( $2 \%$ ) of $\mathrm{O} 2$ was the lowest provided by the incubator and induced a decline in $\mathrm{O} 2$ concentrations from $21 \%$. The responses of lactate dehydrogenase (LDH) and HIF-1 $\alpha$ both confirmed severe hypoxia (SH).[15] Before exposure to $\mathrm{SH}$, the culture media were replaced with a mixture of neurobasal medium and HTK in various percentages $(1 / 8,1 / 4$, and 1/2) of the total volume. We then returned the cells to the hypoxic incubator for $72 \mathrm{~h}$ of treatment.

\section{Cell viability assays.}

LDH levels were measured in the cell culture media $(20 \mu \mathrm{L})$ of two separate dishes at time points of 0, 1, 2, 4, 8, 24, 48, and $72 \mathrm{~h}$ using a commercial kit (Roche Applied Science, Indianapolis, IN, USA), as described previously.[16] The advantage of the LDH assay is that it allows for continual monitoring of cell viability. We used an MTT assay to measure cell viability. Briefly, cells were cultured with or without various percentages of HTK. The medium was then removed, and the cells were washed three times with PBS (pH 7.4). MTT (5 mg mL-1 in PBS) was then added to the cells for $4 \mathrm{~h}$ at $37^{\circ} \mathrm{C}$. MTT formazan crystals were then dissolved in DMSO and the optical density (O.D.) measured using an ELISA plate reader (Amersham-Pharmacia Biotech, Piscataway, NJ, USA) at $570 \mathrm{~nm}$. Cell viability (\%) was calculated using the following formula: (viable cells) $\%=(\mathrm{O} . \mathrm{D}$. of treated sample/O.D. of control sample) $\times 100$.

Exogenous $\mathrm{H} 2 \mathrm{O} 2$ treatment in cortical neurons.

As our results showed that there was an increase in $\mathrm{H} 2 \mathrm{O} 2$ release after the neurons were exposed to $\mathrm{SH}$, we exogenously administered $\mathrm{H} 2 \mathrm{O} 2$ to the neurons to mimic oxidative stress caused by $\mathrm{SH} . \mathrm{H} 2 \mathrm{O} 2$ was added directly to the culture medium at concentrations of 100,400 , and $800 \mu \mathrm{M}$. Cell viability was evaluated at the time points mentioned previously.

Induction of rat brain ischemic damage by asphyxia.

For the in vivo portion of this project, we induced asphyxia in a rat model, as described previously.[17] Briefly, rats were anesthetized with pentobarbital sodium $(50 \mathrm{mg} / \mathrm{kg}$ intraperitoneally) and intubated for breathing control and recording of respiratory patterns. The left carotid artery was then isolated and cannulated using a PE 50 catheter for antegrade solution delivery. The left femoral artery was cannulated for the recording of blood pressure and heart rate. The endotracheal tube was clamped to induce asphyxia for $4 \mathrm{~min} 30 \mathrm{~s}$ (rats who underwent this duration of asphyxia are referred to as the $4^{\prime} 30^{\prime \prime}$ group) or $6 \mathrm{~min} 30 \mathrm{~s}$ (the $6^{\prime} 30^{\prime \prime}$ group). We slowly 
infused $200 \mu \mathrm{L}$ of saline or HTK via the left carotid artery catheter within the first minute of asphyxia in all rats. After induction of aCA, standard external CPR and intravenous bosmin (epinephrine) injections were carried out. Controlled ventilation, using pure O2, was extended for 60 min after return of spontaneous circulation (ROSC). The rats were extubated, their wounds closed, and placed in plastic cages and observed continuously for $60 \mathrm{~min}$ and then intermittently for another 3 days. A neurological deficit (ND) evaluation was performed on the day of asphyxia (day 0) and after asphyxia on days 1, 2, and 3. After 3 days, anesthesia was re-induced for blood sampling and brain perfusion. We prepared the brains for determination of H2O2 and NOX4 mRNA levels.

\section{Neurological deficit (ND) score}

The ND scoring system is presented in Table 1 and has been described previously.[18] ND scores were obtained from two independent observers, with a third observer serving as an arbiter if there were any discrepancies.

Table 1. ND scoring system in rat asphyxia.

\begin{tabular}{|c|c|c|}
\hline & & Score \\
\hline \multirow[t]{2}{*}{ Level of consciousness } & $\begin{array}{c}\text { Attempt to explore } \\
\text { spontaneously }\end{array}$ & 2 \\
\hline & $\begin{array}{l}\text { No attempt to explore } \\
\text { spontaneously }\end{array}$ & 0 \\
\hline \multirow[t]{2}{*}{ Corneal reflex } & Present & 2 \\
\hline & Absent & 0 \\
\hline \multirow[t]{2}{*}{ Respiration } & Normal & 2 \\
\hline & Abnormal & 0 \\
\hline \multirow{2}{*}{$\begin{array}{l}\text { Righting reflex } \\
\text { (attempting to right self when placed on back) }\end{array}$} & Present & 2 \\
\hline & Absent & 0 \\
\hline \multirow[t]{2}{*}{ Coordination } & Normal & 2 \\
\hline & Worst & 0 \\
\hline \multirow[t]{3}{*}{ Movement activity (Legs/tail movement) } & Normal & 2 \\
\hline & Stiff & 1 \\
\hline & Paralyzed & 0 \\
\hline
\end{tabular}

Total score: $12=$ normal, $0=$ brain dead.

Quantitation of $\mathrm{H}_{2} \mathrm{O}_{2}$ in culture medium and brain cortex.

We collected the culture medium and cortical brain tissues after various treatments, and $\mathrm{H} 2 \mathrm{O} 2$ was measured using Amplex red (Molecular Probes, Eugene, OR, USA).[19] Amplex red is a sensitive fluorogenic substrate, which reacts with $\mathrm{H} 2 \mathrm{O} 2$ with a 1:1 stoichiometry to produce highly fluorescent resorufin. Briefly, $200 \mu \mathrm{M}$ Amplex red and $1 \mathrm{U} / \mathrm{mL}$ horseradish peroxidase were added to $20 \mu \mathrm{L}$ of culture medium, tissue homogenates of brain cortex, or a standard $\mathrm{H} 2 \mathrm{O} 2$ solution in PBS ( $\mathrm{pH}$ 7.4). The samples were incubated for $30 \mathrm{~min}$ in 96-well microplates in the dark and at room temperature. Fluorescence intensity was measured using an automatic microplate reader (model KC4, Bio-Tek Instruments, Winooski, VT, USA) at an excitation wavelength of $530 \mathrm{~nm}$ and an emission wavelength of $590 \mathrm{~nm}$. After subtracting background fluorescence, $\mathrm{H} 2 \mathrm{O} 2$ concentrations in the culture media were calculated on the basis of an $\mathrm{H} 2 \mathrm{O} 2$ standard curve.

Western blot analysis for protein expression. 
The expression of full-length (total) caspase 3, cleaved caspase 3 (an indicator of apoptosis), NOX2, NOX4 (indicators of oxidative stress), HIF-1 $\alpha$ (an indicator for hypoxia), and actin were examined by immunoblot analysis in the cultured neurons and brain tissue, as described previously.[16] Primary antibodies against above proteins were obtained from Santa Cruz Biotechnology (Santa Cruz, CA, USA). Briefly, equal amounts of cytosolic protein were separated in denaturing SDS polyacrylamide gels and electrophoretically transferred to polyvinylidene difluoride membranes (Amersham, Little Chalfont, UK). The membranes were then incubated with the appropriate primary antibody (sc-1225, 1:1000 for caspase 3; sc-5827, 1:1000 for NOX2; sc-21860, 1:2500 for NOX4; sc-10790, 1:2000 for HIF- $1 \alpha$; sc-8432, 1:1000 for actin) overnight at $4{ }^{\circ} \mathrm{C}$. After washing, the membranes were incubated for $1 \mathrm{~h}$ at room temperature with the corresponding horseradish peroxidase-conjugated secondary antibodies (1:200; Vector Laboratories, Burlingame, CA, USA). Bound antibodies were visualized using an enhanced chemiluminescence kit (Amersham-Pharmacia Biotech) and Kodak film. Band density was measured semiquantitatively using an image analysis system (Diagnostic Instruments, Sterling Heights, MI, USA). The amount of each protein was expressed relative to the amount of actin.

Measurement of NOX activity in brain tissue.

NADH $(0.1 \mathrm{mmol} / \mathrm{L})$ was used as a substrate for NOX activity assay, as described previously.[20] Salmon testis DNA was added to the reaction mixture to stabilize ethidium fluorescence and increase the sensitivity of the assay. Enzyme activity is presented as fluorescence units/10 s/mg protein.

Quantitative real-time PCR for NOX4 expression.

RNA was extracted using a commercial kit (RareRNA, Bio-East Technology, Taipei, Taiwan), as previously described,[21] and cDNA was synthesized at $42{ }^{\circ} \mathrm{C}$ for $45 \mathrm{~min}$ [reaction mixture: $2 \mu \mathrm{g}$ RNA, $5 \mu \mathrm{g}$ of poly(dT)15 oligonucleotide primer (Life Technologies), and exposed to 200 units of reverse transcriptase (Moloney murine leukemia virus; Promega, Madison, WI, USA)]. Quantitative RT-PCR was performed in an ABI StepOne Plus system (Applied Biosystems, Foster City, CA, USA). PCR was performed using $100 \mathrm{ng}$ of cDNA and $30 \mu \mathrm{mol}$ of primers (total reaction volume, $20 \mu \mathrm{L}$ ) using the SYBR Green PCR master mix kit, according to the manufacturer's instructions (Applied Biosystems). The following primers were used for PCR: NOX4, 5'-GGA TCA CAG AAG GTC CCT AGC-3' (forward) and 5'-AGA AGT TCA GGG CGT TCA CC-3' (reverse); glyceraldehyde 3-phosphate dehydrogenase (GAPDH), 5'-TTA GCA CCC CTG GCC AAG G-3' (forward) and $5^{\prime}$-CTT ACT CCT TGG AGG CCA TG-3' (reverse). The cycling conditions were as follows: $95^{\circ} \mathrm{C}$ for $20 \mathrm{~s}$, followed by 40 cycles of $95^{\circ} \mathrm{C}$ for $1 \mathrm{~s}$ and $60^{\circ} \mathrm{C}$ for $20 \mathrm{~s}$. A melting curve analysis was performed at the end of each PCR experiment. All reactions were run in duplicate. The $\Delta \mathrm{Ct}$ (threshold cycle) was calculated by subtracting the raw $\mathrm{Ct}$ values for GAPDH from the raw $\mathrm{Ct}$ values for the target gene, thereby providing information about relative changes in gene expression. Changes in NOX4 expression were calculated as $2-\Delta \mathrm{Ct}$ and expressed as the fold change relative to that of the $4^{\prime} 30^{\prime \prime}$ group.

\section{Statistical Analysis}

All data are expressed as means \pm standard errors of the mean (S.E.M.). Statistical analysis was performed using analysis of variance, or analysis of variance followed by the Newman-Keuls method for multiple comparisons between groups. A P value $<0.05$ was considered significant.

\section{Results}

The effect of HTK solution during normoxia was tested on neuron cells. As Figure 1A shows, the change in the percentage of LDH that was released increased gradually during normoxia, as hours passed during the observation period. When the proportion of HTK solution increased in the culture medium, the percentage change of $\mathrm{LDH}$ release increased, relative to the $\mathrm{SH}$ group, as the 
duration of HTK exposure increased, becoming statistically significant at $72 \mathrm{~h}$. Thus, substituting parts of the culture medium with HTK resulted in more neural cell damage during the normoxic condition. HTK is not a qualified culture media for use with neural cells in normoxic environments.
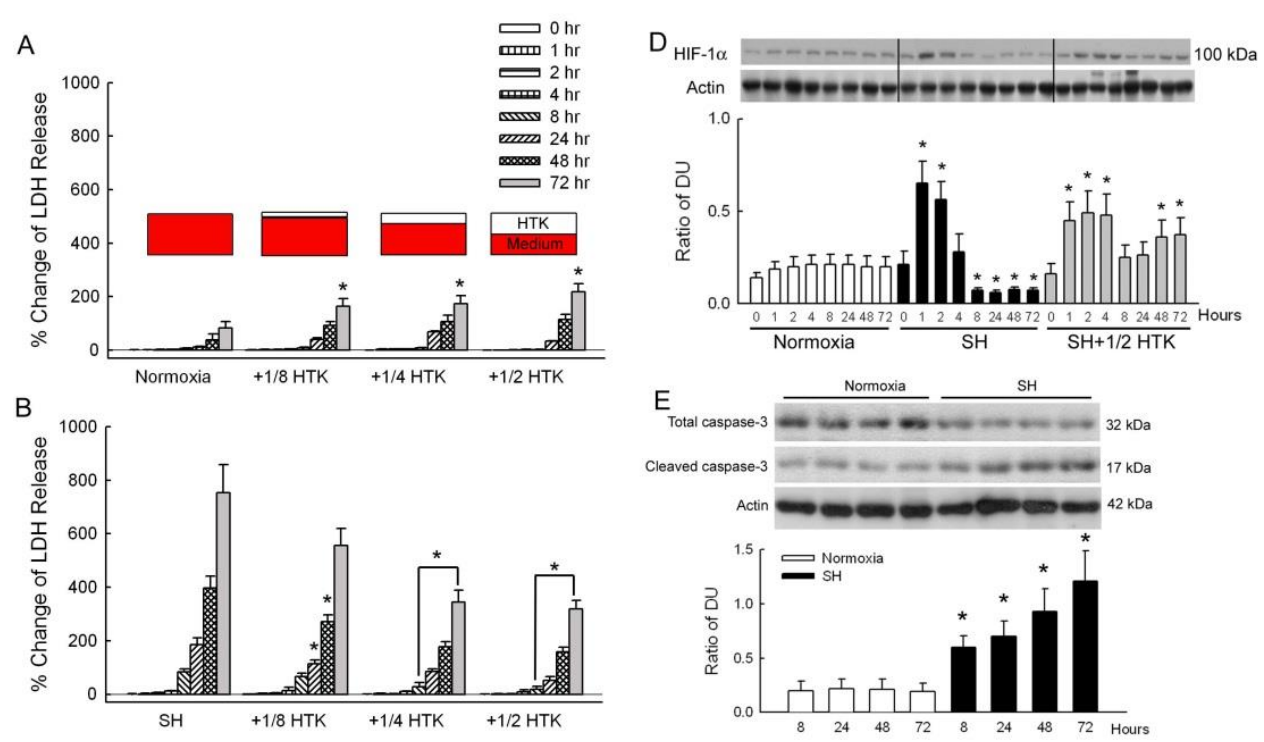

C
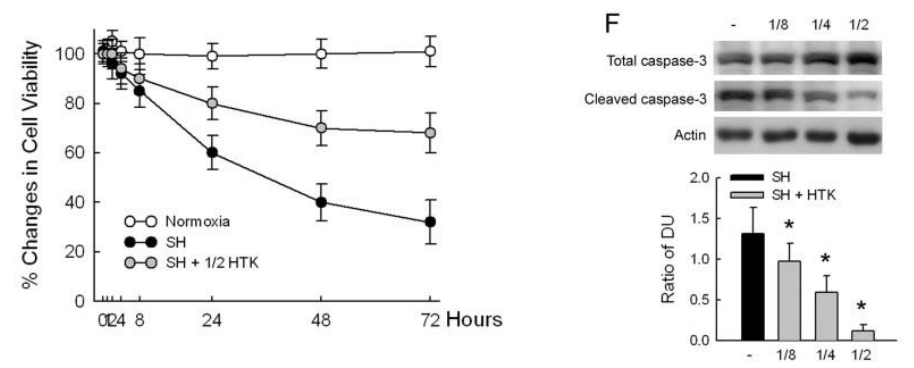

Figure 1. The response of cultured rat cortical neurons during normoxia or severe hypoxia (SH) using different ratios of HTK (histidine-tryptophan-ketoglutarate solution) in volume. (A) During normoxia condition, increasing proportion of HTK in the culture media seems to be harmful. (B) During SH conditions, a higher proportion of HTK would lead to lower LDH (lactate dehydrogenase) released significantly, (C) using 1/2 HTK in volume, cell viability under SH improved significantly. (D) HIF-1 $\alpha$ (hypoxia-induced factor- $1 \alpha$ ) had steady expression in the normoxia control group. The steep elevation over the first few hours of $\mathrm{SH}$ is consistent as reported, but declined rapidly from $8 \mathrm{~h}$ thereafter, indicating not much new HIF-1 $\alpha$ production. Using HTK, the steep increases could still be observed, but there was another plateau after $8 \mathrm{~h}$ of SH. This suggests that HIF-1 $\alpha$ was produced during $\mathrm{SH}$ while under the protection of HTK. (E) The ratio of cleaved caspase- 3 to total caspase- 3 increased significantly as $\mathrm{SH}$ duration increased, indicating increasing apoptosis activity as $\mathrm{SH}$ was prolonged. (F) At $72 \mathrm{~h}$, as the proportion of HTK increased, the ratio of cleaved caspase-3 to total caspase-3 significantly decreased, compared with the $\mathrm{SH}$ group. This indicates that apoptosis is hindered on the presence of HTK. ( $N=6$ of experiences performed at each time point, ${ }^{*} P<0.05$ in Figure 1A, 1B, 1D, 1E as comparing with normoxia control, and $P<0.05$ in $1 \mathrm{~F}$ compared with the SH group.)

During $\mathrm{SH}$, the percentage change of LDH increased significantly after $8 \mathrm{~h}$, as shown in Figure 1B. Using 1/8 HTK solution in the culture medium, the percentage change of LDH decreased significantly at 24 and $48 \mathrm{~h}$, comparing with the $\mathrm{SH}$ group. If the proportion of HTK solution increased to $1 / 4$ or $1 / 2$, the percentage change of LDH decreased significantly at $8,24,48$, and $72 \mathrm{~h}$. The protective effects of HTK solution to cultured neuronal cells in SH were evidenced by the significantly decreased percentage change of LDH, compared with the SH group, at the same time points. 
Cell viability was evaluated in the normoxic group, $\mathrm{SH}$ group, and $\mathrm{SH}+1 / 2 \mathrm{HTK}$. The results are presented in Figure 1C. Cell viability was well preserved in the normoxic group and decreased gradually to $32 \%$ at $72 \mathrm{~h}$ in the $\mathrm{SH}$ group. Substituting half the culture medium with HTK solution significantly increased cell viability, compared with the SH group, at 24, 48, and $72 \mathrm{~h}$. Although viability decreased to $68.5 \%$ at $72 \mathrm{~h}$, it remained more than two times greater than the SH group.

Within the normoxia group, HIF-1 $\alpha$ maintained at a stable level during the observation period, as seen in Figure 1D. Exposing the cell cultures to hypoxic conditions in the SH group increased HIF- $1 \alpha$ levels dramatically at 1 and $2 \mathrm{~h}$. HIF- $1 \alpha$ then decreased after $8 \mathrm{~h}$ to levels below those of the normoxia group. Regarding SH $+1 / 2$ HTK, HIF- $1 \alpha$ increased significantly after ischemia. Although there was a decrease at 8 and $24 \mathrm{~h}$, the HIF- $1 \alpha$ levels were still higher than those of the normoxia group. HIF-1 $\alpha$ levels increased and remained high at 48 and $72 \mathrm{~h}$ intervals.

The ratio of cleaved caspase- 3 to total caspase- 3 remained low during the study period for the normoxia group, as shown in Figure 1E. But it increased with the advancing of the hypoxic period for the SH group. This may have been due to increased apoptosis within the neural cells following $\mathrm{SH}$. The ratio at $72 \mathrm{~h}$ decreased as the proportion of HTK increased, reaching statistical significance even when the culture media consisted of only $1 / 8 \mathrm{HTK}$. For the $\mathrm{SH}+1 / 2 \mathrm{HTK}$, the ratio at $72 \mathrm{~h}$ was even decreased relative to the levels of the normoxia controls. Though there was a tendency toward, and an increased amount of, total caspase- 3 at $72 \mathrm{~h}$, the ratio of cleaved caspase- 3 was significantly decreased if HTK was present.

During the observation period in the normoxia condition, the concentration of $\mathrm{H} 2 \mathrm{O} 2$ increased slightly, but exposure to the hypoxic environment peaked $\mathrm{H} 2 \mathrm{O} 2$ concentrations at $24 \mathrm{~h}$, remaining high until 72 (Figure 2A). In Figure 4B, use of 1/4 HTK significantly reduced $\mathrm{H} 2 \mathrm{O} 2$ production during $\mathrm{SH}$ throughout the whole observation period. The levels of NOX2 and NOX4 were measured at $72 \mathrm{~h}$. The expression of NOX2 was not influenced by the presence of HTK during SH, but NOX4 expression decreased significantly as we titrated up the proportion of HTK during SH. 

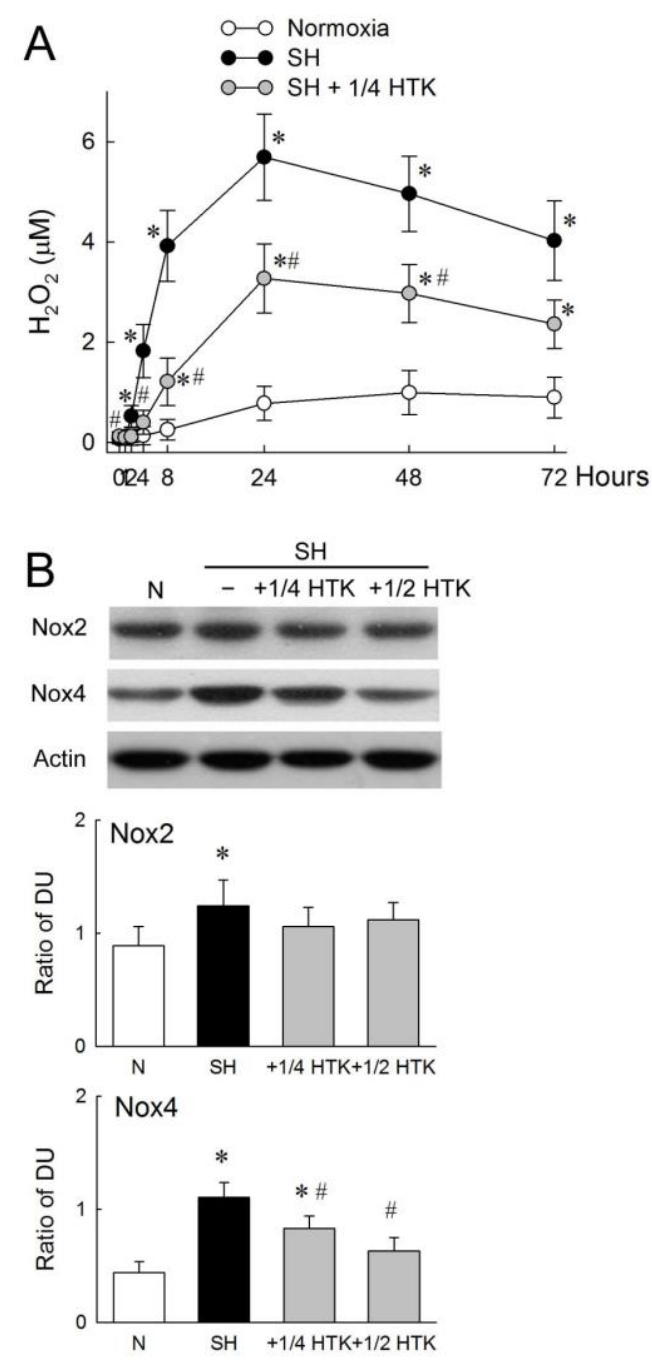

Figure 2. The concentration of $\mathrm{H}_{2} \mathrm{O}_{2}$ and the gene expression of $\mathrm{NADPH}$ oxidase 2 (NOX2) and NADPH oxidase 4 (NOX4) measured during the severe hypoxia $(\mathrm{SH})$ period. (A) The concentration of $\mathrm{H}_{2} \mathrm{O}_{2}$ increased significantly after $2 \mathrm{~h}$ of $\mathrm{SH}$, peaking at $24 \mathrm{~h}$. It remained high at 48 and $72 \mathrm{~h}$. When using 1/4 histidine-tryptophan-ketoglutarate (HTK) solution, the increase of $\mathrm{H}_{2} \mathrm{O}_{2}$ concentration was obviously attenuated, though still significantly higher than normoxia control. (B) At $72 \mathrm{~h}$, the expression of NOX2 increased significantly in the SH group comparing to normoxia control, but the difference was less obvious if HTK was used. The expression of NOX4 also increased significantly in the SH group, but with 1/2 HTK supplement, this increase was no longer significant. The degrees of increment with HTK presence were significantly lower than the SH group also. ( $N=6$ of experiences performed at each time point, ${ }^{*}: P<0.05$ comparing to normoxia control, \#: $P<0.05$ comparing to SH group)

In Figure 3A, the protective effect of HTK, in association with HIF-1 $\alpha$, was also demonstrated by the percentage change of LDH release during ischemic exposure with or without the HIF-1 $\alpha$ antagonist. Using an HIF-1 antagonist (400083) on the SH group with HTK, we increased the percentage change of LDH release; however, the levels remained lower than those observed in the SH group. The addition of an HIF- $1 \alpha$ antagonist did not remove all the protective effects of HTK on neuron cells. This indicates the protective effects of HTK might not have resulted solely as a consequence of elevated HIF-1 levels. 
A
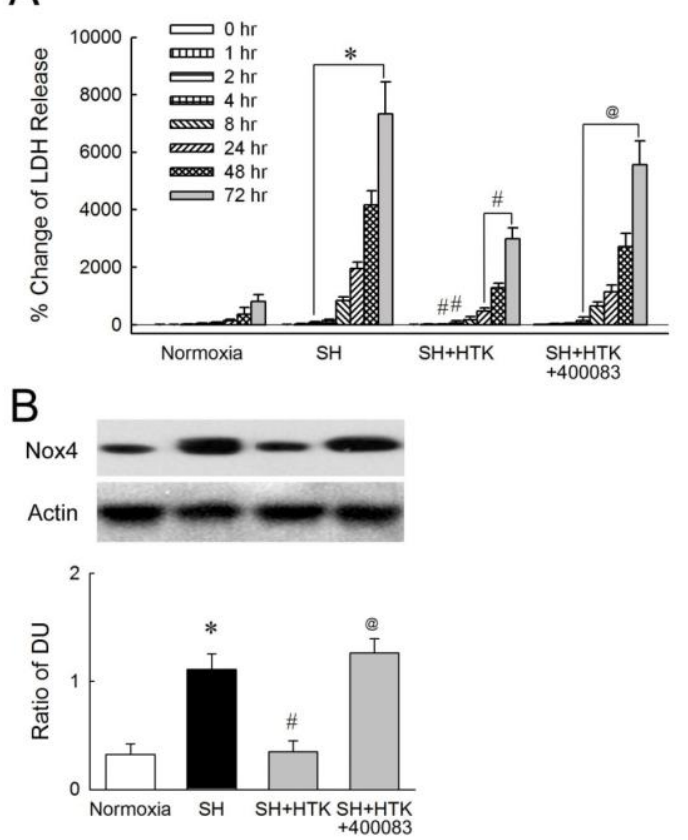

Figure 3. The functional importance of hypoxia-induced factor $1 \alpha$ (HIF- $1 \alpha)$ during severe hypoxia $(\mathrm{SH})$ was evaluated with the HIF-1 $\alpha$ antagonist 400083. (A) Release of lactate dehydrogenase (LDH) was attenuated after SH through usage of HTK $(\mathrm{SH}+\mathrm{HTK}$; HTK stands for histidine-tryptophan-ketoglutarate solution). After using HIF-1 $\alpha$ antagonist 400083, the LDH release increased comparing to the SH + HTK group. (B) HIF-1 $\alpha$ was connected to the activation of NADPH oxidase 4 (NOX4). At $72 \mathrm{~h}$, HTK decreased the expression of NOX4 during SH. The addition of the HIF-1 $\alpha$ antagonist 400083 completely reversed the effect of HTK usage on NOX4 expression. The protective effect of HTK might not be confined to the HIF-1 $\alpha$ pathway, but the expression of NOX4 might solely depend on HIF- $1 \alpha$. ( $N=6$ of experiences performed at each time point, ${ }^{*}: P<0.05$ comparing to normoxia control, \#: $P<0.05$ comparing to SH group, @: $P<0.05$ comparing to $\mathrm{SH}+\mathrm{HTK}$ group)

In Figure 3B, the level of NOX4 expression at $72 \mathrm{~h}$ decreased after using HTK, but returned to levels similar to those of the SH group if the HIF-1 $\alpha$ antagonist was added. HIF-1 does not seem to increase NOX4 levels under the influence of HTK, as indicated by our results.

In Figure 4A, exposed to PBS slowly increased the percentage change of LDH release, as the duration of exposure increased. Challenges with different $\mathrm{H} 2 \mathrm{O} 2$ concentrations resulted in significant increases on the percentage change of LDH release after $2 \mathrm{~h}$, and even after $1 \mathrm{~h}$ when challenged with $800 \mu \mathrm{M} \mathrm{H} 2 \mathrm{O} 2$. When HTK was present, neuronal cells became more resistant to $\mathrm{H} 2 \mathrm{O} 2$ damage. In the PBS $+1 / 8$ HTK group (Figure 4B), the exposure of different concentrations of $\mathrm{H} 2 \mathrm{O} 2$ resulted in a significant decrease in percentage change of LDH release from 1 to $24 \mathrm{~h}$, comparing to the PBS group treated with the same $\mathrm{H} 2 \mathrm{O} 2$ concentrations at the same time point. The protective effect decreased on 48 and $74 \mathrm{~h}$. Increasing HTK proportion to $1 / 4$ would prolong the protective effect to $48 \mathrm{~h}$, and for PBS $+1 / 2$ HTK group, the decrease of the percentage change of LDH release was significantly low even at $72 \mathrm{~h}$ (Figure $4 \mathrm{C}$ and $4 \mathrm{D}$ ). $\mathrm{H} 2 \mathrm{O} 2$ treatment not only reduces the viability of neuronal cells but may also impair branching linkage during dendritic outgrowth (Figure 4E). 


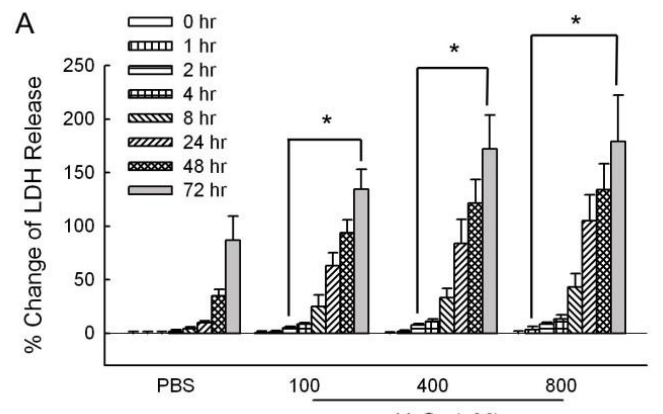

E

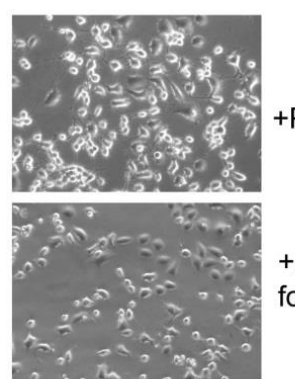

B

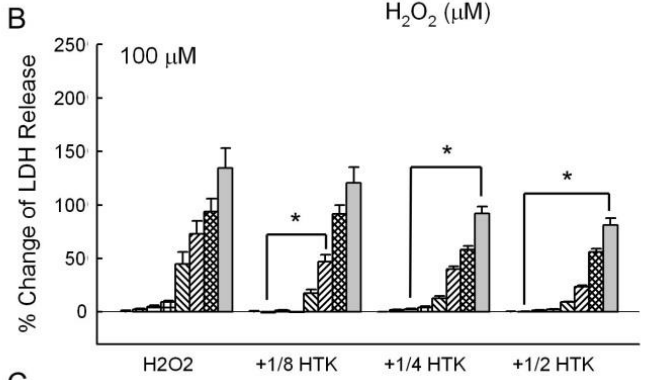

F
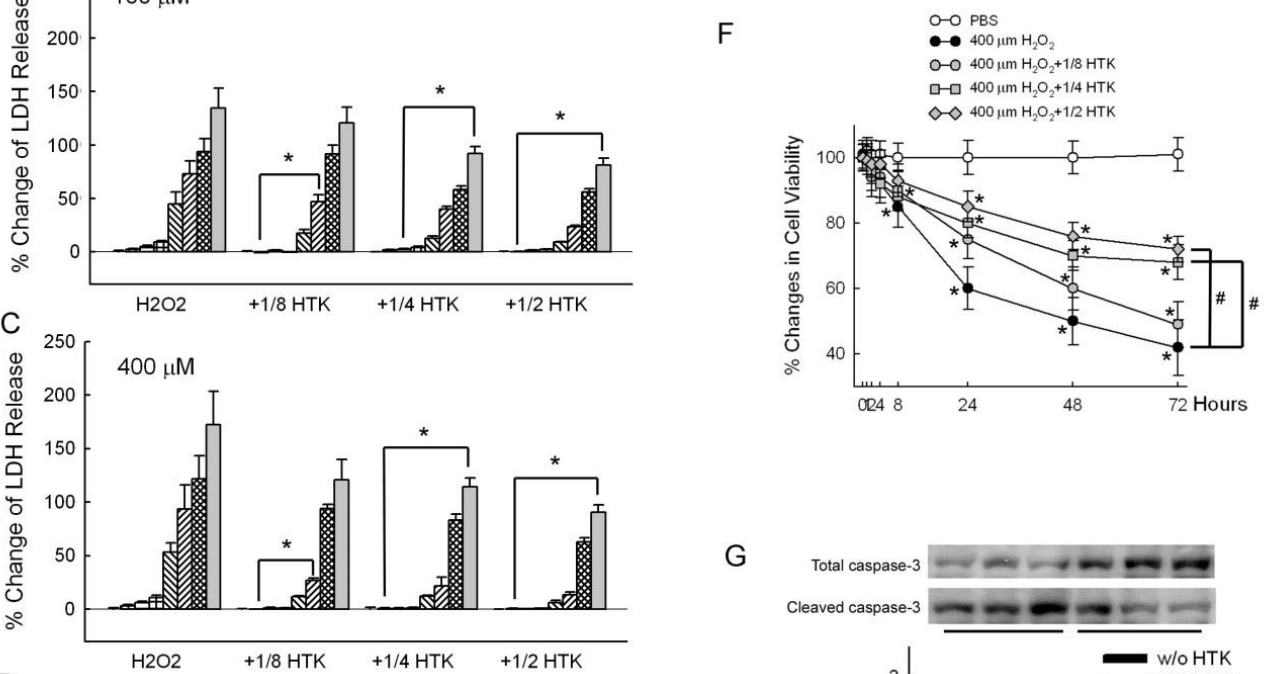

G

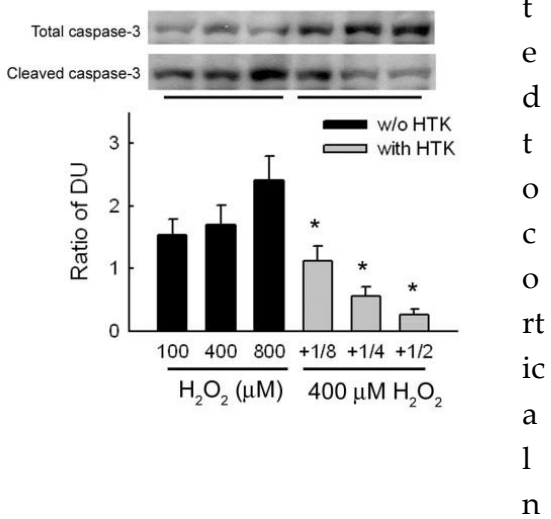

euron cultures obtained from rats, mimicking oxidative stress during $\mathrm{SH}$ (severe hypoxia). (A) As the concentration of the added $\mathrm{H}_{2} \mathrm{O}_{2}$ increased, the percentage change in $\mathrm{LDH}$ (lactate dehydrogenase) release increased significantly. [ ${ }^{*}: P<0.05$ comparing to phosphate-buffered saline (PBS) only at the same observation time length] For each $\mathrm{H}_{2} \mathrm{O}_{2}$ concentration, histidine-tryptophan-ketoglutarate solution (HTK) replaced PBS by $1 / 8,1 / 4$, and $1 / 2$, and all subgroups showed significantly less 
percentage change of $\mathrm{LDH}$, comparing to the same $\mathrm{H}_{2} \mathrm{O}_{2}$ concentration controls without $\mathrm{HTK}(\mathrm{B}, \mathrm{C}$, and D). ( ${ }^{*}: P<0.05$ comparing to the same $\mathrm{H}_{2} \mathrm{O}_{2}$ group without HTK) (E) While attempting a cell viability test, it was difficult when $800 \mu \mathrm{M} \mathrm{H}_{2} \mathrm{O}_{2}$ was used. Small amount of viable cells could be found under the microscope after $48 \mathrm{~h}$ exposure to $800 \mu \mathrm{M} \mathrm{H}_{2} \mathrm{O}_{2}$. (F) The $\mathrm{PBS}+400 \mu \mathrm{m} \mathrm{H}_{2} \mathrm{O}_{2}$ group was used for cell viability test. These results revealed that using $1 / 4$ or $1 / 2$ HTK produced superior cell viability, compared with instances where $1 / 8$ HTK or no HTK was used.( ${ }^{*}: P<0.05$ when comparing to the PBS control, and \#: $P<0.05$ comparing $1 / 2$ or $1 / 4$ HTK with no HTK group) (G) The ratio of cleaved caspase- 3 to total caspase- 3 increased as the concentration of $\mathrm{H}_{2} \mathrm{O}_{2}$ increased. In the $400 \mu \mathrm{M} \mathrm{H}_{2} \mathrm{O}_{2}$ group, this ratio decreased significantly even if only $1 / 8 \mathrm{HTK}$ were used. $\left({ }^{*}: P<0.05\right.$ comparing to $400 \mu \mathrm{m} \mathrm{H} \mathrm{H}_{2}$ without HTK) ( $N=6$ of experiences performed at each time point).

Cell viability was evaluated in the PBS group without $\mathrm{H} 2 \mathrm{O} 2$ and various concentrations of $\mathrm{HTK}$ challenged with $400 \mu \mathrm{M} \mathrm{H} 2 \mathrm{O} 2$. The PBS group showed the worst cell viability at all time points, and as the concentration of HTK increased, the protective effect became obvious. The cell viability of the 1/8 HTK group was significantly better than the $400 \mu \mathrm{M} \mathrm{H} 2 \mathrm{O} 2$ group over the first $24 \mathrm{~h}$, but did not exhibit significant differences at 48 to $72 \mathrm{~h}$. On the other hand, the $1 / 4$ and $1 / 2$ HTK groups all showed significantly better cell viability, through $72 \mathrm{~h}$ of the observation period.

The ratio of cleaved caspase- 3 to total caspase- 3 increased as the concentration of $\mathrm{H} 2 \mathrm{O} 2$ increased in the PBS group where no HTK was used. Once HTK was added, the ratio decreased significantly, and even to a larger scale of decreasing as the proportion of HTK increased from 1/8 to half of the culture medium. The pattern of ratio decreasing by increased non-cleaved caspase- 3 levels and decreased cleaved caspase-3 levels was the same as exposure to $\mathrm{SH}$.

The asphyxia time was measured from the clamping of the endotracheal tube to ROSC. The 4'30" groups had shorter durations of resuscitation, and the 6'30" groups were resuscitated significantly longer, but the difference in resuscitation durations between the saline group and the HTK group was not significant at the same asphyxia time (Figure 5A). For the Bosmin dosage used, the 6'30" groups used nearly twice the dosage of that used by the 4'30" groups. No significant differences were observed between the HTK group and the saline group with the same aCA time (Figure 5B).
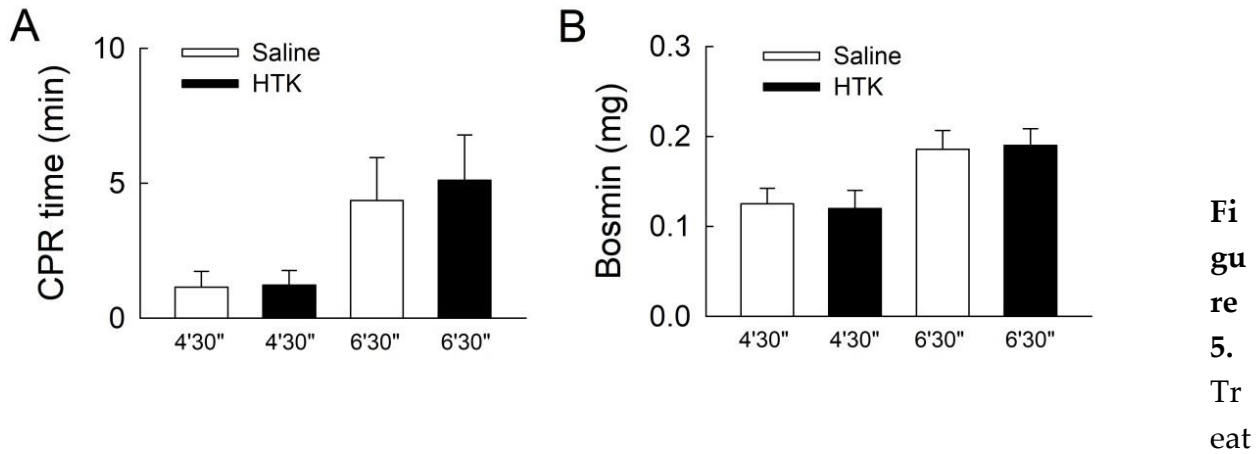

ment of cardiopulmonary resuscitation (CPR) for asphyxial cardiac arrest (aCA) in rats. Note that the CPR time and the bosmin dose for CPR were both similar between groups treated with saline and histidine-tryptophan-ketoglutarate solution (HTK), at the same aCA time.

The HTK usage seemed to increase rat survival from $62.5 \%$ to $75 \%$ for group 4'30", and from $26.7 \%$ to $44.4 \%$ for group $6{ }^{\prime} 30^{\prime \prime}$ at day 3 (Figure 6A). The total ND scores between the HTK and saline subgroups were similar among the 4'30" groups. For the 6'30" groups, the total ND score increased significantly for the HTK subgroup, compared with the saline subgroup, at day 1 and the gap increased gradually to day 3 (Figure 6B). If we looked into each component of total ND score (Figure $6 \mathrm{C})$, it would be clear that all but the respiration score followed this pattern. The respiratory scores of the HTK and saline groups both increased gradually from day 1 to day 3, without statistically significant between-group differences. 
A

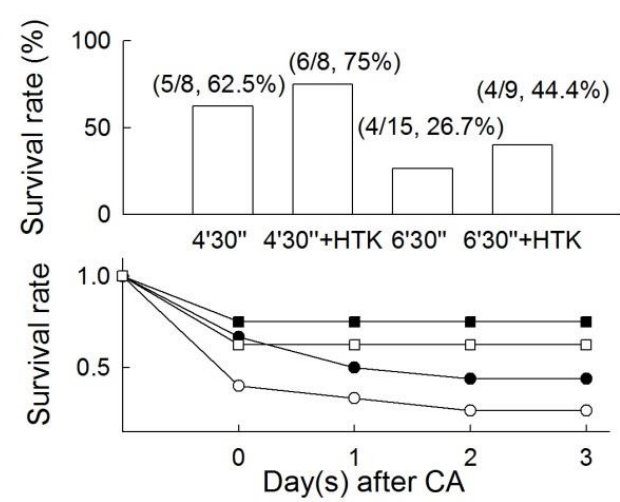

C
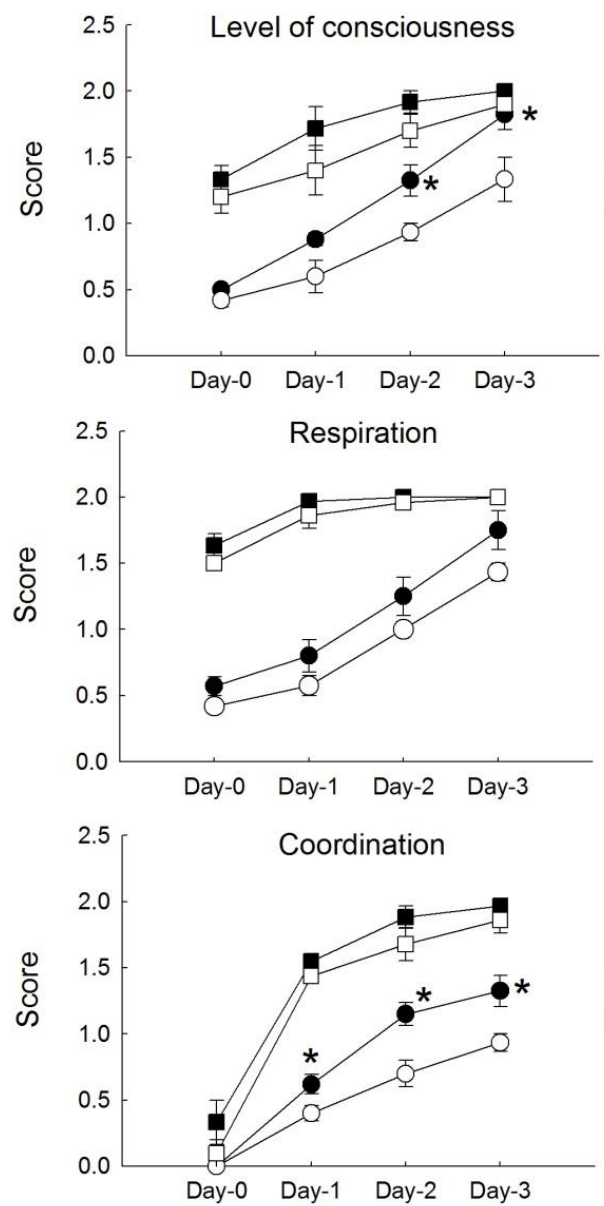

B
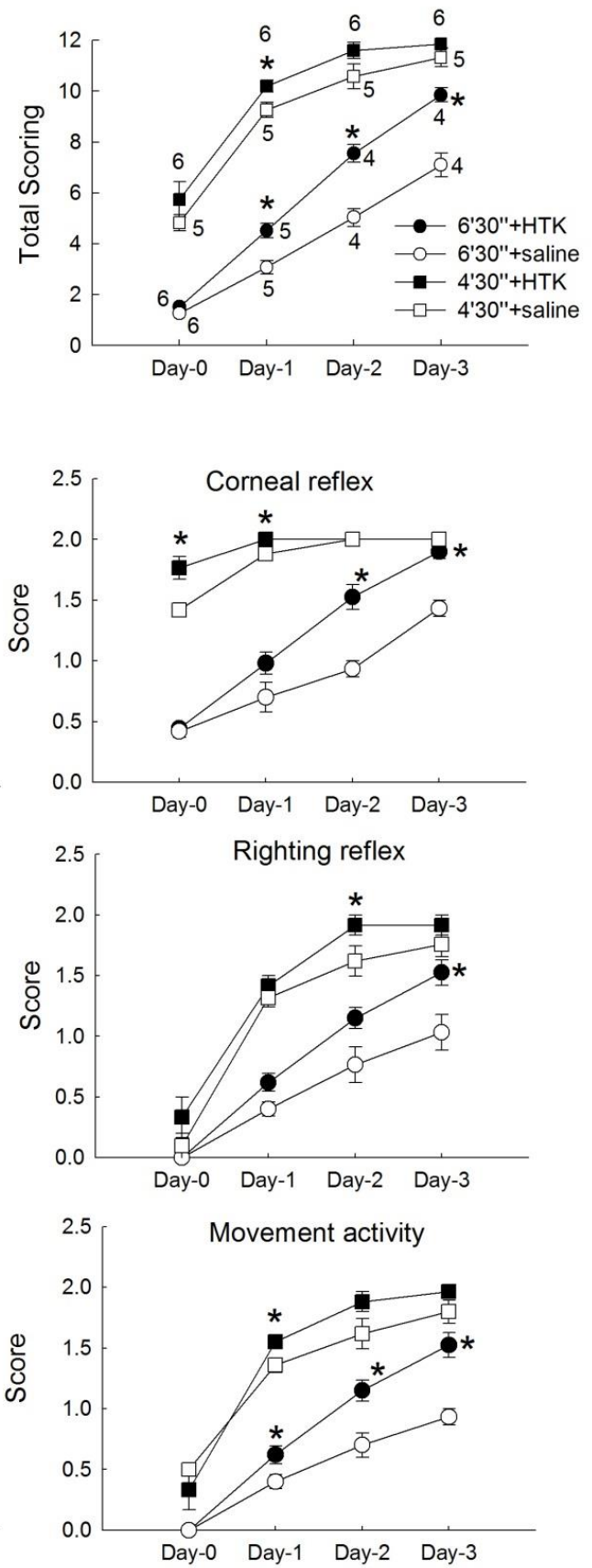

$r$

han-ketoglutarate solution (HTK)-mediated brain protection against asphyxial cardiac arrest (aCA) at 1 to 3 days after asphyxiation of $4 \mathrm{~min} 30 \mathrm{~s}$ (group 4'30") and $6 \mathrm{~min} 30 \mathrm{~s}$ (group 6'30") in the presence of saline or HTK solution. (A) Survival rate on day 3 and the survival rates from day 0 to day 3 are shown. (B) Total neural deficit (ND) scores are shown from day 0 to day 3 . The numbers listed beside each icon on the line chart are the survived and observed number of rats at that time point. ND values were all better in the group 4'30" than in the 6'30"group. Treatment of HTK improved ND scores significantly at day 1 for group 4'30" and from day 1 to day 3 for group 6'30". (C) HTK treatment improved scores on day 3 for group 6 ' 30 ", with the exception of respiration. $\left({ }^{*} P<0.05\right.$ compared with the saline-treated controls with the same duration time of aCA.)

The blood $\mathrm{H} 2 \mathrm{O} 2$ concentrations at $72 \mathrm{~h}$ after ROSC were similar between the HTK and saline groups at each aCA time (Figure 7A). But the $\mathrm{H} 2 \mathrm{O} 2$ concentration of brain cortex remained significantly higher $72 \mathrm{~h}$ after ROSC in the saline group compared with the HTK group (Figure 7B). 
Both the expression of NOX4 mRNA and NOX4 activity showed this similarity. High NOX4 mRNA expression, with increased NOX4 activity, could be observed in the saline group, compared with the HTK group in the 6'30" group (Figure 7C and 7D).
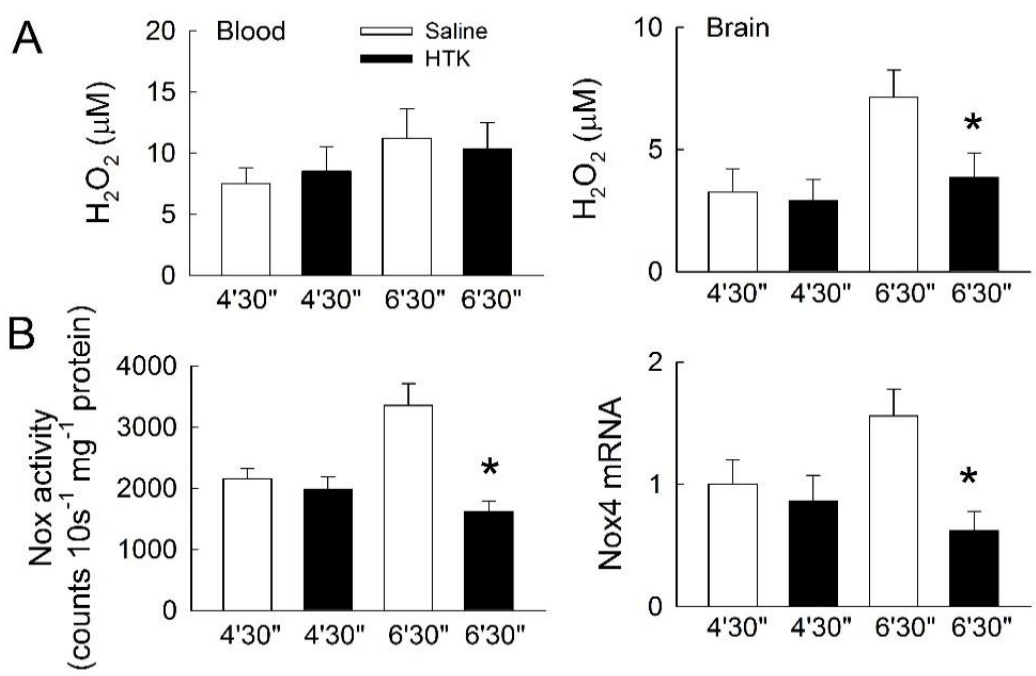

\begin{abstract}
Figure 7. Effects of (histidine-tryptophan-ketoglutarate solution (HTK) on $\mathrm{H}_{2} \mathrm{O}_{2}$ production and brain tissue NADPH oxygenase 4 (NOX4) expression. (A) Changes in $\mathrm{H}_{2} \mathrm{O}_{2}$ levels in blood and brain cortex that are prepared and isolated from rats 3 days after cardiopulmonary resuscitation (CPR) and cardiac arrest (CA). (B) Changes in NOX activity (the left panel) and NOX4 mRNA expression (the right panel) in the rat brain cortex after 3 days of treatment. ( $N=6$ of experiences performed at each time point, ${ }^{*} P<0.05$ compared with the saline-treated controls with the same induction time of CA.)
\end{abstract}

\title{
4. Discussion
}

We encountered ischemic brain injury on patients rescued by CPR during our daily practice. We applied cardioplegic solutions, which were used to protect the heart during ischemic periods of cardiac surgery, to the brain and tested HTK solution as a potential neuroprotective agent, due to its success on other organs.

The protective effects of HTK on brain cells during ischemic periods, compared with those found in the normoxia control groups, were well demonstrated by the degree of LDH release and cell survival tests. Our results demonstrated that release of LDH due to cell damage, either by SH or $\mathrm{H} 2 \mathrm{O} 2$, was significantly decreased when we increased the proportion of HTK in the culture medium. These results indicated that, in the presence of HTK, the cell damage caused by prolonged ischemia or $\mathrm{H} 2 \mathrm{O} 2$ exposure was attenuated. Using $1 / 2$ HTK in the culture medium, the cell survival percentage increased dramatically to $68.5 \%$ ( $\mathrm{p}<0.05$ ) comparing to $32 \%$ for those without HTK after ischemia for $72 \mathrm{~h}$. HTK also increased cell survival percentage from $42 \%$ to $72 \%(\mathrm{p}<0.05)$ after exposed to $400 \mu \mathrm{M} \mathrm{H} 2 \mathrm{O} 2$ for $72 \mathrm{~h}$. This is the first report of HTK usage on in vitro neuronal cells with definite protective effect during hypoxic condition.

We find the pattern of HIF-1 level changes during the ischemic period interesting. Without HTK, HIF-1 increased sharply at $1 \mathrm{~h}$ after exposure to the hypoxic environment. But the level of HIF-1 started decreasing at $2 \mathrm{~h}$ and decreased dramatically at $8 \mathrm{~h}$ of persisted ischemia, even lower than the sham group. This surge of HIF-1 was well illustrated in previous studies that showed the degradation of HIF-1 would be hindered in the presence of low O2.[8] With the aid of HTK, this surge of HIF-1 did not seem so abrupt. Although decreased from the peak at 8 and $24 \mathrm{~h}$ of hypoxic exposure, the level of HIF-1 remained significantly higher during the 48 and $72 \mathrm{~h}$ time points. HTK 
seems to keep neuronal cells capable of maintaining a high level of HIF-1, which drives many cellular responses for surviving during periods of hypoxia.

HIF-1 was accused of promoting cell death after ischemia, essentially the opposite of its effects on helping cell survival during periods of ischemia. HIF-1 $\alpha$ and P53 may "conspire to promote a pathological sequence resulting in cell death," according to Halterman et al.[22] Their study showed almost no delayed death of mixed cortical neuronal cells if HIF-1 was blocked by plasmid transfection $20 \mathrm{~h}$ prior to $110 \mathrm{~min}$ of ischemic exposure and evaluated $46 \mathrm{~h}$ after reoxygenation. While in the presence of HIF-1, the death of mixed cortical neuronal cells decreased in p53 knock-out mice.

Another study published by Hoecke et al.[9] connected HIF-1 to caspase-3 and proved that HIF-1 would bind directly to the promoter of the caspase- 3 gene, increasing the amount of caspase- 3 after photothrombotic cerebral ischemia. But reviewing the colocalization of procaspase-3 expression and cleavage with HIF- $1 \alpha$ presented in that study, the pattern was quite intriguing. Inside the infarct core, the expression of HIF- $1 \alpha$ and procaspase- 3 was very low, but procaspase-3 cleavage was observed. On the penumbra region, the expression of HIF- $1 \alpha$ and procaspase- 3 was high and colocalized and so was the cleaved procaspase-3. On the outer unlesioned area, the expression of HIF- $1 \alpha$ and procaspase-3 colocalization was decreased, whereas procaspase- 3 cleavage was faintly expressed.

These two reports can be merged with our results without contradiction. HIF-1 was discovered because of its presence during periods of $\mathrm{SH}$, and it drove many cell responses that helped cells survive in a low-O2 environment. According to the results of a previous study, HIF-1 was found to colocalize with procaspase-3. Our results indicated that the amount of procaspase- 3 increased and the ratio of procaspase- 3 to total caspase- 3 decreased significantly. We therefore suggest that HIF-1 not only increase the expression of cell death genes but also suppress their activation until the condition is longer tolerable for the cell. Thus, the duality of HIF-1 $\alpha$ is not only confined to the activation of hypoxia adaptation genes and interaction between p53 for apoptosis,[23] but might also include the increased expression of the procaspase- 3 gene, in association with the inhibition of the procaspase- 3 activation process.

The expression of NOX4 during hypoxia and in the presence of HTK was not as expected. A previous study showed that direct binding of HIF-1 $\alpha$ to the promoter segment of the NOX4 gene was responsible for the increased expression of NOX4.[11] It also showed high HIF-1 $\alpha$ levels during the first $4 \mathrm{~h}$ of hypoxia and gradually increasing expression of NOX 4 mRNA, peaking at $4 \sim 8 \mathrm{~h}$ after hypoxia. In our study, when the HIF- $1 \alpha$ levels were persistently elevated under the influence of $1 / 2$ HTK in culture media, NOX4 was suppressed to the level of the control group. At the same time, the $\mathrm{H} 2 \mathrm{O} 2$ levels elevated gradually until $24 \mathrm{~h}$ after onset of hypoxia. The elevation of NOX4 expression was also observed $12-24 \mathrm{~h}$ after performing transient middle cerebral artery occlusion in another study.[24] Oxidative stress, blood-brain-barrier leakage and neuronal apoptosis were all decreased if NOX4 had been knocked out or if NOX4 function was blocked after the ischemic period. The protective effect of HTK on neuronal cells during hypoxia might also relate to suppressed NOX4 expression by persistently elevated HIF- $1 \alpha$.

In the second part of this study, we presented the effect of HTK infusion during aCA. Here, exposure to HTK improved the neurological scores of rats in the first 3 days after aCA. NOX4 had already been identified as an important factor relating to brain autotoxicity and blood-brain-barrier disruption after temporary middle cerebral artery occlusion.[25] The NOX4 knock-out rats in that study had decreased infarction size with improved neurological and motor functions. Similar functional improvement was observed in our study. The improvement of ND scores was more prominent in the HTK 6'30" group, comparing to the saline control group. This result was associated with decreased NOX4 function and decreased $\mathrm{H}_{2} \mathrm{O} 2$ concentrations that occurred in brain tissue and blood at day 3. In brain tissue of the saline group, persistent elevation of NOX4 mRNA levels, NOX4 function and $\mathrm{H} 2 \mathrm{O} 2$ concentrations at day 3 indicated that the ischemic insult might result in persistent damage after complete reoxygenation (so-called reperfusion injury). As described in the first part of this report, the decrease of NOX4 activity could be associated with persistent elevation of 
HIF-1 $\alpha$ during the hypoxic ischemic phase, due to the presence of HTK. The infusion of HTK during the ischemia in the second part of this report showed the same result. This suggests that HTK might be suitable for use during resuscitations for improving neurological outcomes.

The guidelines for resuscitation have evolved during recent years. Early defibrillation, continuous chest compressions with minimal interruption, early epinephrine injections, and transport to capable hospitals are processes with wide acceptance over recent years,[26] and the target temperature management for comatose patients after resuscitation granted its level I recommendation in 2015.[27] But pharmacological agents to increase neurological recovery were not yet widely available. Erythropoietin and its derivatives were effective in reducing ischemic size within an isolated heart model[28] and brain infarction model,[29] in animal studies. Hydrogen inhalation combined with target temperature management improved study animal survival and neurological recovery after resuscitation from ventricular fibrillation.[30] Despite these good results, few clinical trials were reported.[31] Use of HTK holds another advantage in that it is a substance that is already in widespread clinical use.

On limitation of this study was that we did not elucidate the connection between persistently elevated HIF-1 levels with procaspase-3 and NOX4. HTK was infused at the beginning of asphyxia instead of the start of CPR. Further, all neural cell studies were conducted without hypothermia. The linkage of HIF-1 with procaspase-3 and NOX4 warrants further investigation. The other two were designed to better demonstrate the possible benefits of HTK treatment. Further studies with more closely mimic "real world" clinical scenarios would bring more evidences, given the encouraging results of this pioneer study.

\section{Conclusions}

In conclusion, HTK solution maintained high HIF-1 $\alpha$ levels in a neurological cell ischemia study, potentially leading to increased procaspase-3 production, suppressed procaspase-3 activation, and decreased NOX4 expression. HTK infusion during aCA increased short-term neurological scores in survived animals; this was associated with decreased NOX4 expression. This is the first report of a possible brain-protection solution for patients undergoing resuscitation, or in cases where long-term brain ischemia is needed to perform cardiac surgery. These results were positive, and further investigation on this topic might have encouraging results.

Supplementary Materials: None

\section{Author Contributions:}

conceptualization, Jiun Hsu, and Yih-Sharng Chen; methodology, Ming-Chih Ma and Yih-Sharng Chen.; validation, Chih-Hsien Wang and Ming-Chih Ma; formal analysis, Jiun Hsu, Jou-Wei Lin and Yih-Sharng Chen; investigation, Jiun Hsu, Yih-Sharng Chen.; resources, Shu-Chien Huang, Juey-Jen Huang and Ming-Chih Ma.; data curation, Ming-Chih Ma and Yih-Sharng Chen.; writing-original draft preparation, Jiun Hsu.; writing-review and editing, Jiun Hsu, Ming-Chih Ma and Yih-Sharng Chen.; visualization, Yung-Wei Chen and Shengpin Yu.; supervision, Yih-Sharng Chen.; project administration, Jiun Hsu and Yih-Sharng Chen.; funding acquisition, Ming-Chih Ma and Yih-Sharng Chen, .

Funding: This research was partially supported by 106-2314-B-002-234-MY3, 106-105-2314-B-07-2314-B-030-012 from Ministry of Science and Technology, Taiwan 
Conflicts of Interest: The authors declare no conflict of interest.

\section{References}

1. Chen, Y. S.; Chao, A.; Yu, H. Y.; Ko, W. J.; Wu, I. H.; Chen, R. J. C.; Huang, S. C.; Lin, F. Y.; Wang, S. S.Analysis and results of prolonged resuscitation in cardiac arrest patients rescued by extracorporeal membrane oxygenation. J. Am. Coll. Cardiol. 2003, 41, 197-203, doi:10.1016/S0735-1097(02)02716-X.

2. Huang, S.-C.; Wu, E.-T.; Chen, Y.-S.; Chang, C.-I.; Chiu, I.-S.; Wang, S.-S.; Lin, F.-Y.; Ko, W.-J.Extracorporeal membrane oxygenation rescue for cardiopulmonary resuscitation in pediatric patients. Crit. Care Med. 2008, 36, 1607-13, doi:10.1097/CCM.0b013e318170b82b.

3. Dragancea, I.; Rundgren, M.; Englund, E.; Friberg, H.; Cronberg, T.The influence of induced hypothermia and delayed prognostication on the mode of death after cardiac arrest. Resuscitation 2013, 84, 337-42, doi:10.1016/j.resuscitation.2012.09.015.

4. Augoustides, J. G. T.; Stone, M. E.; Drenger, B.Novel approaches to spinal cord protection during thoracoabdominal aortic interventions. Curr. Opin. Anaesthesiol. 2014, 27, 98-105, doi:10.1097/ACO.0000000000000033.

5. Bretschneider, H. J.Myocardial protection. Thorac. Cardiovasc. Surg. 1980, 28, 295-302.

6. Fridell, J. A.; Mangus, R. S.; Tector, A. J.Clinical experience with histidine-tryptophan-ketoglutarate solution in abdominal organ preservation: A review of recent literature. Clin. Transplant. 2009, 23, 305-312.

7. Semenza, G. L.; Wang, G. L.A nuclear factor induced by hypoxia via de novo protein synthesis binds to the human erythropoietin gene enhancer at a site required for transcriptional activation. Mol. Cell. Biol. 1992, 12, 5447-5454, doi:10.1128/MCB.12.12.5447.Updated.

8. Tekin, D.; Dursun, A. D.; Xi, L.Hypoxia inducible factor 1 (HIF-1) and cardioprotection. Acta Pharmacol. Sin. 2010, 31, 1085-1094, doi:10.1038/aps.2010.132.

9. VanHoecke, M.; Prigent-Tessier, A. S.; Garnier, P. E.; Bertrand, N. M.; Filomenko, R.; Bettaieb, A.; Marie, C.; Beley, A. G.Evidence of HIF-1 functional binding activity to caspase-3 promoter after photothrombotic cerebral ischemia. Mol. Cell. Neurosci. 2007, 34, 40-47, doi:10.1016/j.mcn.2006.09.009.

10. Vallet, P.; Charnay, Y.; Steger, K.; Ogier-Denis, E.; Kovari, E.; Herrmann, F.; Michel, J. P.; Szanto, I.Neuronal expression of the NADPH oxidase NOX4, and its regulation in mouse experimental brain ischemia. Neuroscience 2005, 132, 233-238, doi:10.1016/j.neuroscience.2004.12.038.

11. Diebold, I.; Petry, A.; Hess, J.; Görlach, A.The NADPH oxidase subunit NOX4 is a new target gene of the hypoxia-inducible factor-1. Mol. Biol. Cell 2010, 21, 2087-96, doi:10.1091/mbc.E09-12-1003.

12. Matsushima, S.; Kuroda, J.; Ago, T.; Zhai, P.; Ikeda, Y.; Oka, S.; Fong, G.-H.; Tian, R.; Sadoshima, J.Broad suppression of NADPH oxidase activity exacerbates ischemia/reperfusion injury through inadvertent downregulation of hypoxia-inducible factor- $1 \alpha$ and upregulation of peroxisome proliferator-activated receptor- $\alpha$. Circ. Res. 2013, 112, 1135-49, doi:10.1161/CIRCRESAHA.111.300171.

13. Hendrickx, H. H. L.; Safar, P.; Miller, A.Asphyxia, cardiac arrest and resuscitation in rats. II. Long term behavioral changes. Resuscitation 1984, 12, 117-128, doi:10.1016/0300-9572(84)90063-7.

14. Ma, M. C.; Qian, H.; Ghassemi, F.; Zhao, P.; Xia, Y.Oxygen-sensitive ??-opioid receptor-regulated survival and death signals: Novel insights into neuronal preconditioning and protection. J. Biol. Chem. 2005, 280, 16208-16218, doi:10.1074/jbc.M408055200.

15. Wenger, R.; Kurtcuoglu, V.; Scholz, C.; Marti, H.; Hoogewijs, D.Frequently asked questions in hypoxia research. Hypoxia 2015, 35, doi:10.2147/HP.S92198.

16. Phan, W. L.; Huang, Y. T.; Ma, M. C.Interleukin-27 Protects cardiomyocyte-like H9c2 cells against metabolic syndrome: Role of STAT3 signaling. Biomed Res. Int. 2015, 2015, doi:10.1155/2015/689614.

17. Gao, C. J.; Niu, L.; Ren, P. C.; Wang, W.; Zhu, C.; Li, Y. Q.; Chai, W.; Sun, X. D.Hypoxic preconditioning attenuates global cerebral ischemic injury following asphyxial cardiac arrest through regulation of delta opioid receptor system. Neuroscience 2012, 202, 352-362, doi:10.1016/j.neuroscience.2011.11.060.

18. Huang, C.-H.; Hsu, C.-Y.; Chen, H.-W.; Tsai, M.-S.; Cheng, H.-J.; Chang, C.-H.; Lee, Y.-T.; Chen, W.-J.Erythropoietin Improves the Postresuscitation Myocardial Dysfunction and Survival in the Asphyxia-Induced Cardiac Arrest Model. Shock 2007, 28, 53-58, doi:10.1097/shk.0b013e31802f0218. 
19. Lin, C.-S.; Lee, S.-H.; Huang, H.-S.; Chen, Y.-S.; Ma, M.-C.H 2 O 2 generated by NADPH oxidase 4 contributes to transient receptor potential vanilloid 1 channel-mediated mechanosensation in the rat kidney. Am. J. Physiol. - Ren. Physiol. 2015, 309, F369-F376, doi:10.1152/ajprenal.00462.2014.

20. Huang, H. S.; Ma, M. C.High sodium-induced oxidative stress and poor anticrystallization defense aggravate calcium oxalate crystal formation in rat hyperoxaluric kidneys. PLoS One 2015, 10, 1-19, doi:10.1371/journal.pone.0134764.

21. Ma, M.-C.; Wang, B.-W.; Yeh, T.-P.; Wu, J.-L.; Chung, T.-H.; Tsui, K.; Chiang, C.-F.; Huang, A.-J.; Huang, Y.-T.Interleukin-27, a novel cytokine induced by ischemia-reperfusion injury in rat hearts, mediates cardioprotective effects via the gp130/STAT3 pathway. Basic Res. Cardiol. 2015, 110, 22, doi:10.1007/s00395-015-0480-y.

22. Halterman, M. W.; Miller, C. C.; Federoff, H. J.Hypoxia-inducible factor-1alpha mediates hypoxia-induced delayed neuronal death that involves p53. J. Neurosci. 1999, 19, 6818-24.

23. Suzuki, H.; Tomida, A.; Tsuruo, T.Dephosphorylated hypoxia-inducible factor 1alpha as a mediator of p53-dependent apoptosis during hypoxia. Oncogene 2001, 20, 5779-88, doi:10.1038/sj.onc.1204742.

24. Kleinschnitz, C.; Grund, H.; Wingler, K.; Armitage, M. E.; Jones, E.; Mittal, M.; Barit, D.; Schwarz, T.; Geis, C.; Kraft, P.; Barthel, K.; Schuhmann, M. K.; Herrmann, A. M.; Meuth, S. G.; Stoll, G.; Meurer, S.; Schrewe, A.; Becker, L.; Gailus-Durner, V.; Fuchs, H.; Klopstock, T.; deAngelis, M. H.; Jandeleit-Dahm, K.; Shah, A. M.; Weissmann, N.; Schmidt, H. H. H. W.Post-stroke inhibition of induced NADPH Oxidase type 4 prevents oxidative stress and neurodegeneration. PLoS Biol. 2010, 8, doi:10.1371/journal.pbio.1000479.

25. Casas, A. I.; Geuss, E.; Kleikers, P. W. M.; Mencl, S.; Herrmann, A. M.; Buendia, I.; Egea, J.; Meuth, S. G.; Lopez, M. G.; Kleinschnitz, C.; Schmidt, H. H. H. W.NOX4-dependent neuronal autotoxicity and BBB breakdown explain the superior sensitivity of the brain to ischemic damage. Proc. Natl. Acad. Sci. 2017, 114, 201705034, doi:10.1073/pnas.1705034114.

26. Ewy, G. A.; Bobrow, B. J.Cardiocerebral Resuscitation. J. Intensive Care Med. 2016, 31, 24-33, doi:10.1177/0885066614544450.

27. Callaway, C. W.; Donnino, M. W.; Fink, E. L.; Geocadin, R. G.; Golan, E.; Kern, K. B.; Leary, M.; Meurer, W. J.; Peberdy, M. A.; Trevonne, M.; Zimmerman, J. L.HHS Public Access. Circulation 2015, 132, S465-S482, doi:https://doi.org/10.1161/CIR.0000000000000262.

28. Chan, C.-Y.; Chen, Y.-S.; Lee, H.-H.; Huang, H.-S.; Lai, Y.-L.; Chen, C.-F.; Ma, M.-C.Erythropoietin protects post-ischemic hearts by preventing extracellular matrix degradation: role of Jak2-ERK pathway. Life Sci. 2007, 81, 717-23, doi:10.1016/j.lfs.2007.07.013.

29. Erbayraktar, S.; Grasso, G.; Sfacteria, A.; Xie, Q. -w.; Coleman, T.; Kreilgaard, M.; Torup, L.; Sager, T.; Erbayraktar, Z.; Gokmen, N.; Yilmaz, O.; Ghezzi, P.; Villa, P.; Fratelli, M.; Casagrande, S.; Leist, M.; Helboe, L.; Gerwein, J.; Christensen, S.; Geist, M. A.; Pedersen, L. O.; Cerami-Hand, C.; Wuerth, J.-P.; Cerami, A.; Brines, M.Asialoerythropoietin is a nonerythropoietic cytokine with broad neuroprotective activity in vivo. Proc. Natl. Acad. Sci. 2003, 100, 6741-6746, doi:10.1073/pnas.1031753100.

30. Hayashida, K.; Sano, M.; Kamimura, N.; Yokota, T.; Suzuki, M.; Ohta, S.; Fukuda, K.; Hori, S.Hydrogen inhalation during normoxic resuscitation improves neurological outcome in a rat model of cardiac arrest independently of targeted temperature management. Circulation 2014, 130, 2173-2180, doi:10.1161/CIRCULATIONAHA.114.011848.

31. Taccone, F. S.; Crippa, I. A.; Dell'Anna, A. M.; Scolletta, S.Neuroprotective strategies and neuroprognostication after cardiac arrest. Best Pract. Res. Clin. Anaesthesiol. 2015, 29, 451-464, doi:10.1016/j.bpa.2015.08.005. 


\section{8 of 18}

32. Author 1, A.B. Title of Thesis. Level of Thesis, Degree-Granting University, Location of University, Date of Completion.

33. Title of Site. Available online: URL (accessed on Day Month Year). 